\title{
Construction Efficiency and Environmental Impact of Wind Power Delivery Transmission Lines in Arctic Region
}

\author{
Chunhua Hu, Yongjun Xia, Jiancheng Wan and Zeming Song \\ China Electric Power Research Institute
}

Keywords: Arctic region, transmission line project, construction efficiency

Abstract: This paper analyzes the environmental characteristics of the Arctic region and the factors that affect the construction efficiency of power transmission and transformation. Considering the climate and environmental characteristics of the Arctic region, the paper goes further to discuss the protective measures for operators and operating machinery used in the construction of power transmission lines in the Arctic region. It also analyzes the environmental impact of power transmission and transformation construction in the Arctic region.

\section{Introduction}

The Arctic region has harsh natural conditions in which severe coldness, high humidity, strong winds and other extreme weather conditions challenge the limit of human existence. It is an extreme challenge to construct transmission lines in the Arctic region per se. During the construction process, in order to overcome the harm of climate and environment to the human body and machines, create suitable working and living environment, and protect the health of workers involved in the power transmission project in the Arctic region, to master use, protection and maintenance methods for construction equipment that can be used in a low temperature environment can improve work efficiency and ensure smooth progress of the construction.

\section{Impact of Environmental Factors in Arctic on Construction Efficiency of Power Transmission Line Projects}

The construction efficiency of power transmission line projects in the Arctic region is mainly affected by temperature changes, circadian time and geological environment. In terms of temperature, the winter is long and cold while the summer is short and cool in the Arctic region, with a large annual temperature range. In terms of circadian time, the night is long in winter and short in warm seasons, and there are polar days and polar nights. Geologically, the Arctic region is full of permafrost that can form swamps easily on land. The environmental factors in the Arctic region mainly affect the workers and operating machines in construction projects.

\section{Impact of Extreme Coldness on Workers}

Impact of ambient temperature.Since power transmission projects are often field work, workers are directly exposed to severely cold environments. Based on the previous experience in construction during winter in Heilongjiang, the workers could hardly work under an ambient temperature of $-30^{\circ} \mathrm{C}$ and the working efficiency was zero; at an ambient temperature between $-30^{\circ} \mathrm{C}$ and $-20^{\circ} \mathrm{C}$, the working efficiency was greatly decreased to about $50 \%$ of normal work; at an ambient temperature between $-20^{\circ} \mathrm{C}$ and $-10^{\circ} \mathrm{C}$, which is a common level in the Northeast of China, 
the working efficiency was $70 \%$ of the normal level; at an ambient temperatures between $-10^{\circ} \mathrm{C}$ and $0^{\circ} \mathrm{C}$, the labor efficiency was little effected and was about $90 \%$ of the normal level.

Impact of circadian time in regions at high latitudes and with severe coldness. In regions at high latitudes, the winter has short days but long nights, shortening the working time during the day. In regions where polar nights occur, normal operation will not be possible. Depending on the lengths of day in different regions, the reduction of working efficiency can be accurately calculated.

Impact on the health of construction workers. Construction workers generally have bare hand skin temperature at $20^{\circ} \mathrm{C}$ or above to maintain basically normal operating functions. When the skin temperature is reduced to $10-12^{\circ} \mathrm{C}$, the tactile sensitivity would decrease significantly; when it is down to $4-5^{\circ} \mathrm{C}$, the tactile sense (feeling) would be almost completely lost. After the body gets cold, the blood pressure will increase and patients with high blood pressure will be prone to cerebral accidents. Working (such as refrigeration operation) in an environment with great temperature differences can destroy the human body's adaptation to normal seasonal changes. Therefore, workers can feel symptoms like fatigue, malaise, cold, numb and sour hands and feet, toothache, and frequent urination. When workers feel unwell, they will have to take a break, which will cause downsizing and thus affect the input of workers and reduce the overall efficiency.

\section{Impact of Severe Coldness in Arctic Region on Working Machines}

Severe coldness can seriously affect the performance of construction machinery and equipment and thus greatly reduce the working efficiency:

Engine: Among construction machinery and equipment, when engine is used at low temperatures, the evaporation, combustion and low temperature fluidity of fuel will be reduced and cause some difficulties in the startup of diesel engine; at the same time, the power consumption of diesel engine will be large and the working efficiency of the machine will be lowered.

Hydraulic system: The hydraulic oil can become very thick due to the low temperature, and lubricant film can hardly be formed on the pump and motor of stretch equipment, resulting in increased wear and tear; as the hydraulic oil becomes very thick, the oil return is not easy in the pump casing and the oil return pressure is increased to wash the oil seal of spindle head away. The final result will be forced shutdown and the construction is affected.

Power-driven winching: Since the lubricant inside the gearbox becomes thick due to low temperature, the thick lubricant will stick the pin roller beyond the clutch to the locking plate during the braking process and result in brake failure. Due to the impact of low temperature, the mechanical wear of construction machinery and equipment is increased. As a result, the fuel consumption is increased while the brake reliability is reduced. In addition, the hydraulic hoses, rubber seals and metal components will be prone to brittle fracture due to coldness.

\section{Protective Measures against Impact of Severe Coldness in Arctic Region on Construction Efficiency of Power Transmission Line Projects}

Protection for construction workers in severely cold regions. During project construction, it is not only important to establish and improve regional medical, health and other logistics support, it's also necessary to set up appropriate performance pay incentives to fully tap the inherent potential of construction workers and improve the working efficiency while enhancing the stability of the construction team.

In terms of personal care, the diet of workers should be rich in fat, protein and vitamin B1. Protein deficiency can undermine the body's tolerance to coldness. Taking a warm shower after the 
work under the severely cold environment is finished helps to quickly reduce and eliminate the impact of coldness. The stations should be equipped with clothing drying rooms and hot shower rooms.

Use and maintenance of construction machinery in severely cold regions. The engine should be warmed up before it is started: this can reduce the rotational resistance of crankshaft to facilitate the startup. Water-cooled diesel engines are usually warmed up by adding hot water or oversaturated vapor. To heat the engine oil: a safe and reliable method is to inject pre-heated oil in the oil pan. To use the startup fuel: the diesel engine can be started quickly by injecting $10-25 \mathrm{ml}$ primer fluid into its intake chamber.

The battery maintenance should be strengthened: the battery discharges faster in winter, so it should be returned indoor for insulation after the machine is stopped. The specific gravity of the battery electrolyte should be checked to keep at 1.28. In order to avoid too much battery discharge, the charging voltage of the regulator can be increased appropriately.

Suitable grade of light diesel oil should be selected correctly: the grade of light diesel oil represents the freezing point of the diesel, which should be $5-6^{\circ} \mathrm{C}$ lower than the lowest ambient temperature, in order to ensure that the diesel oil is not frozen under the minimum temperature and has good low temperature fluidity.

\section{Impact of Large Power Transmission Project Construction on Ecological Environment in Arctic Region}

The wind power delivery transmission lines in the Arctic region passes through the North Pole and Siberian Plain, where there are moss tundra, shrub tundra and southern-forest tundra woodland, as well as a variety of flora and fauna and environmental protection areas. They are important environmental factors to consider in the construction of large wind power delivery transmission line projects in the Arctic region.

(1) Impact on vegetation

The main construction, construction machinery, transport access roads, construction camps and construction behavior of workers will inevitably disturb local terrestrial crust or compact the earth's surface, thus trampling the vegetation and surface covered layer. As a result, the surface vegetation will be destructed, reducing the food for hoofed wild animals that are herbivorous, and the birds that rest in wetland in winter or all the year round may also be affected. Another result of destructed vegetation can be local desertification of grassland.

(2) Impact on water and atmosphere

Improper or arbitrary emissions of oil containing wastewater, sewage, waste gas, and dust produced from the construction sites or stations and by workers and construction machinery will contaminate local water bodies. Mechanical vehicle exhaust, coal for heating and construction dust will pollute the atmospheric environment.

(3) Impact of solid waste on the environment

The impact of solid waste on the environment: solid waste such as production waste, waste residues, and garbage, when disposed improperly, will affect the vegetation, water, wildlife and pristine natural landscape in natural reserves.

(4) Impact on wildlife

Unreasonable selection and arrangement of spoil ground, sand gravel fields and construction camps and the illegal operations and behaviors on the construction sites and from construction machinery and workers are likely to affect the activities of wildlife in nature reserves.

(5) Impact on the soil environment 
Any actions of construction teams that are designed to allow for the permafrost and that fail to comply with temporary construction programs in different projects will lead to new natural disasters such as thaw depressions, thaw ponds, thaw slumping, and thaw mud and further damage and affect the permafrost environment within the nature reserves.

\section{Conclusion}

To sum up, the special environment and climate in the Arctic region will reduce the construction efficiency of power transmission lines. The environment and climate characteristics of the Arctic region with high latitudes should be fully considered during the construction. The construction should be carried out in summer whenever possible and the construction program and technical measures should be well developed. The construction of wind power delivery transmission lines will adversely affect the ecological environment of the Arctic region. Environmental protection should be guaranteed during the construction of power transmission lines to balance the relationship and resolve the conflict between human development and environmental protection.

\section{References}

1. R. Saidur, N.A. Rahim, M.R. Islam. Environmental impact of wind energy. Renewable \& Sustainable Energy Reviews, 2013

2. N. Council. Environmental Impacts of Wind-Energy Projects, 2007

3. D. Y. C. Leung, Y. Yang. Wind energy development and its environmental impact: A review, Renewable \& Sustainable Energy Reviews, 2012

4. J. F. Decarolis. The economics and environmental impacts of large-scale wind power in a carbon constrained world, 2004

5. A. Arvesen, E. G. Hertwich. Assessing the life cycle environmental impacts of wind power: A review of present knowledge and research needs, Renewable \& Sustainable Energy Reviews, 2012 